\title{
Choosing International Organizations: When Do States and the World Bank Collaborate on Environmental Projects?*
}

\author{
Patrick Bayer \\ University of Mannheim
}

\author{
Christopher Marcoux \\ DePauw University
}

16 December 2013

\author{
Johannes Urpelainen ${ }^{\dagger}$ \\ Columbia University
}

\begin{abstract}
While international cooperation research emphasizes institutional design, states mostly interact with existing organizations. How do states choose organizations for cooperation? We develop a theory of agency choice for development projects, emphasizing the importance of domestic institutions, the scope of cooperation, and the resources of the implementing agency. If states are to cooperate with funding agencies that have abundant resources, such as the World Bank, they must accept more stringent conditions on project implementation. We argue states accept the stringent conditions that resourceful organizations demand if the public goods from project implementation are highly valuable. Empirically, this is the case for democratic states, large projects, and projects that produce national instead of global public goods. We test this theory using data on 2,882 Global Environment Facility (GEF) projects, 1991-2011. The GEF offers an ideal case because various implementing agencies are responsible for the actual projects. States implement projects in collaboration with the World Bank, which has the most expertise and resources among the GEF's implementing agencies, if their regime type is democracy, the project size is large, and the benefits are primarily national. Qualitative evidence sheds light on causal mechanisms.
\end{abstract}

\footnotetext{
${ }^{*}$ An earlier version of this paper was presented at the 6th Political Economy of International Organizations Conference, held at the Universities of Mannheim and Heidelberg, February 7-9, 2013. We would like to thank all conference participants for their comments and are particularly indebted to Katharina Michaelowa, Ulrich Wagner, Axel Dreher, and three anonymous reviewers for their helpful feedback.

${ }^{\dagger}$ Corresponding author. Assistant Professor, Department of Political Science, Columbia University. 420 West 118 th Street, 712 IAB. New York, NY 10027, USA. Phone: +1-734-757-0161. Email: ju2178@ columbia.edu.
} 


\section{Introduction}

Project funding is a central form of collaboration between recipients and international funding agencies (Dreher, Sturm, and Vreeland 2009; Kilby 2009; Winters 2010). If a recipient country seeks assistance to implement a project, such as building a road or a hospital, it can propose the project to a number of possible funders, ranging from the World Bank (WB) to regional development banks and bilateral lenders. We examine how potential recipient countries form partnerships with funding agencies for project implementation.

Over time, international organizations have proliferated (Pevehouse, Nordstrom, and Warnke 2004) and "regime complexes" have become common (Hofmann 2011; Keohane and Victor 2011; Johnson and Urpelainen 2012). This same phenomenon is often referred to as "forum shopping" (Busch 2007; Sykes 2008), "regime shifting" (Helfer 2004), or "institutional choice" (Jupille and Snidal 2006; Jupille, Mattli, and Snidal 2013). As scholars emphasize the diversity of institutionalized cooperation in world politics, the choice of partners for collaboration has become increasingly important. However, researchers have made little progress in explaining how states choose their international partners (see Humphrey and Michaelowa 2013: for an exception). Most studies of project implementation focus on a specific funding agency (Nielson and Tierney 2003; Fleck and Kilby 2006; Kilby 2009; Lyne, Nielson, and Tierney 2009; Winters 2010) and/or donor incentives (Rodrik 1995; Milner 2006). This lack of attention to partner choice is troubling for several reasons. First, endogenous partner choice means that studies of donor-recipient collaboration may suffer from selection bias, as recipients strategically select donors. Second, partner choice is a natural avenue to an improved understanding of the broader issue of state choice among international organizations.

Consider the funding decisions of the world's leading agency specializing in promoting global environmental protection, the Global Environment Facility (GEF). The GEF is a capital fund that offers purely concessionary grants to fund project implementation, while the implementation of each project is the responsibility of a variety of agencies, especially the WB and the United Nations Development Programme (UNDP). Developing country recipients have been suspicious of WB influence in the GEF since the beginning (Sharma 1996), and recipients have financial motivations for avoiding the WB. Among the GEF's various implementing agencies, the WB consistently requires greater recipient co-financing than do other agencies. Figure 1 shows the GEF's mean shares of project costs when projects are implemented through the WB and the UNDP, the two largest GEF agencies. The remaining project costs, not covered by GEF 
agencies, have to be covered by recipient co-financing from the recipient government, the private sector, non-governmental organizations, and sometimes other donors. As co-financing is complementary, lower contributions by the WB or the UNDP translate into higher project costs for recipient states. Over the first decade of GEF operations, the WB typically required co-financing of roughly half of project costs. The UNDP, in contrast, required only twenty percent. In recent years, co-financing requirements have increased at both agencies, reflecting changes to GEF allocation rules and the increased prominence of climate mitigation projects in the energy sector that often draw private capital (Clémençon 2006; Bayer, Marcoux, and Urpelainen 2013). However, as recently as 2011 there remained a substantial gap between the two.

[Figure 1 about here.]

This presents a puzzle. Recipients understand they incur greater costs when partnering with the WB than with other implementing agencies. If recipient countries have a general preference to minimize their financial responsibility with respect to project implementation, why do they continue to solicit WB partnership? While the overall share of GEF projects implemented by the WB has indeed decreased slightly over time, this simply reflects the fact that the number of GEF agencies has grown from three to ten since $1991{ }^{1}$ Despite this proliferation in institutional diversity, the WB continues to be a common implementing agency for GEF projects, especially in the case of large projects.

We present a theory of how states choose partners among international funders for projects that generate national and/or global public goods. As states choose international partners for their projects, their key trade-off is between agency resources - the funding agency's available expertise and capital for project implementation - and the conditions - financing by the recipient and policy change requirements - attached to the project. ${ }^{2}$ Analogous to price discrimination in oligopolistic competition, the most resourceful funding agencies can afford to only fund projects that are designed in view of their own priorities. When a state considers a project, it must decide if the additional conditions imposed by the funding agency with the best resources and expertise are worth the extra cost. Since the agency's resources influence the quality

\footnotetext{
${ }^{1}$ Originally, all GEF projects were implemented by one or a combination of three executing agencies: the UNDP, the United Nations Environment Programme (UNEP), and the WB. As of 2012, there are ten such agencies, including a number of additional $\mathrm{UN}$ agencies and regional development banks.

${ }^{2}$ Based on a coding of 50 random GEF projects, we ascertain in the online appendix available on the journal's webpage that GEF agencies contribute on average about $19 \%$ of project funds, confirming that financial resources are one of the most important contributions that funding agencies bring to the table. Funding from other sources, such as private capital (12\%), NGOs (2\%), or other concessionary, non-recipient funding $(5 \%)$, is more limited.
} 
of project implementation, the recipient's valuation of the public goods produced determines how much it values collaboration with a resourceful agency. Resourceful agencies also have their own biases and preferences that shape the price tag on their collaboration.

Since state choice of international organizations depends on the endogenous behavior of said organizations, we rely on a simple formal model that allows us to account for strategic behavior. A state's valuation of the public goods from the project determines its willingness to pay for having an implementing agency with considerable resources. The model, whose equilibrium characterization is found in the supplementary online appendix, endogenizes both the state's choice of the implementing agency and the implementing agency's choice of conditionality. The model accounts both for the state's demand for agency partners and the agency's supply of project conditions, with three hypotheses:

1. Since democracies ascribe a higher value to public goods (Bueno de Mesquita et al. 2003), they are more inclined to collaborate with resourceful agencies than are autocracies.

2. Since the stakes are higher for large projects, states implement them with resourceful agencies more than they implement small projects.

3. Since states value national public goods more than global public goods (Barrett 2003), states implement projects emphasizing the former with resourceful agencies more often than they implement the latter.

If the most resourceful implementing agency is partial to democracy and prefers to implement large projects that produce global public goods, these tendencies are further strengthened.

Empirically, we analyze how states have chosen among different funding agencies to implement projects funded by the Global Environmental Facility (GEF). As stated above, the GEF is a capital fund that offers fully concessional grants for development projects that contribute to environmental protection and would not be implemented without the GEF's grant. The GEF is ideal for our test because it delegates the implementation of its projects to various implementation agencies, and the choice of these agencies is, to a large extent, at the discretion of the recipient states. Our data set covers all of the 2,882 bilateral projects the GEF has funded during the 1991-2011 period.

We find that both recipient and project characteristics shape agency choice. Democracies implement 
projects with the WB more often than autocracies do. Moreover, countries are more likely to select the WB as their implementation partner for projects that are large or focused on mitigating local, instead of global, environmental problems. These findings are consistent with the idea that states select resourceful implementing agencies when they ascribe a high value to successful project implementation.

Qualitative evidence sheds light on causal mechanisms. We interviewed the country focal points of four GEF recipients for information about the role of the host country and the implementing agency in project implementation. While the sample is not representative, the qualitative evidence supports the findings from the quantitative analysis. While the implementing agency is not entirely passive in initiating projects, the host country's leading role is equally clear. Moreover, the country focal points emphasized the WB's advantages in the implementation of large and/or technically complex projects.

Further data analysis allows us to reject plausible alternative explanations. First, the WB could favor democracies because the most influential donors are democracies. The number of democracies on the Bank's Executive Board does not modify the effect of democracy on agency choice, suggesting that recipient demand and institutional preferences are decisive. Second, it could be that the WB implements large projects because other agencies are simply too small to do so. Even if we focus on projects of small and medium size, larger investment is positively associated with the likelihood of WB implementation.

Jupille and Snidal (2006) suggest that when a single focal institution is not present, competitive dynamics may arise. International organizations differentiate themselves to attract selection by states, and states "shop" among institutions. Although helpful in understanding forum shopping, this logic has less to say about the sources of state preferences, and thus less to say about likely patterns of institutional selection. We develop a theory of agency selection based on recipient interests and by offering a systematic test of that theory.

Our results also demonstrate that recipients value local projects differently from global ones. If recipients are less likely to select agencies based on institutional resources, this has troubling implications for the use of development finance to promote environmental public goods. The globally most useful projects may be implemented by the least apt implementing agencies, because the recipients are unwilling to pay the cost of working with a more resourceful agency. 


\section{A Theory of International Agency Choice}

Our theory focuses on how recipient countries select among possible funders for development projects. Recipient countries are interested in implementing projects that are only feasible with external assistance. The recipient countries can "shop" for a partner agency. The agency behaves strategically, however, maximizing an objective function that reflects its own bureaucratic incentives and those of the "collective principal" comprising states that control the organization (Nielson and Tierney 2003). In this setting, the interaction of the demand and supply for agency resources can be accounted for.

One key dimension are the resources of the funding agency. This is because resources - capital and expertise - jointly determine an agency's ability to implement projects. Funding agencies differ in regard to their expertise in project implementation and investment. Some funding agencies have decades of experience, competent and motivated staff, and a portfolio of tens of thousands major projects. This is particularly true of organizations with large capital endowments that allow them to accumulate substantial experience across multiple domains and implement large projects. Smaller agencies often have much less experience and face difficulties in retaining the most competent officials due to competition from the private sector and other public organizations. In other words, large organizations can tap into a more impressive body of experience and knowledge in project implementation.

These dimensions play a key role in how states form partnerships with international funders for their projects. In any particular context, some agencies have an advantage over others. The position of a given agency depends on the context. For example, a large development bank with a proven track record could be ideal for investment projects, whereas a smaller and leaner technical agency could be better for technical cooperation and capacity building.

Accounting for both supply and demand factors, the first section analyzes in greater detail the trade-off between more and less resourceful funding agencies. While one might initially expect all states to reach out to the most resourceful agencies, resulting in a monopoly of the most resourceful agency, our formal analysis suggests otherwise. When states implement projects that they do not find particularly valuable, they are willing to collaborate with less resourceful agencies that demand a lower fee for project implementation. In contrast, states that value their putative projects the most are willing to pay the price, perhaps in the form of conditionality, imposed by the agencies with the most resources. In the model, competing implementing 
agencies endogenously select the project condition. As such, the model is fully strategic and, although our substantive focus is on the recipient side, also accounts for the supply side.

The second section derives three hypotheses on the covariates of agency choice. First, we argue that democratic states value agency resources more than autocratic states. Second, we expect large projects to carry a resource premium. Finally, we expect projects prioritizing national rather than global public goods to hold a bias toward agencies with abundant resources.

\subsection{Agency Resources: Benefits, Costs, and Selection}

As states consider their alternatives for implementing projects, they can choose from a variety of potential agencies. This decision is informed by the expected costs and benefits of collaborating with different donors. Costs associated with project implementation typically include lesser or greater co-financing requirements on the part of the recipient state. Moreover, agencies may stipulate specific conditions to be met for project funding to be disbursed. The international agency may also insist on issue linkage.

For example, World Bank project number P002978, which involved US\$11.8M in concessional financing from the World Bank's International Development Agency (IDA), assisted Uganda in natural resource management at the community level. World Bank approval was conditional on Uganda accepting a number of implementation guidelines and, notably, Uganda's creation of a National Ministry for the Environment (World Bank 2006). The World Bank also commonly imposes extra-project conditions, linking broader reforms to project approval. World Bank project number P008519 provided US\$20M in IDA financing to the Kyrgyz Republic to assist it in attracting private investment in petroleum exploration and production. World Bank approval in this case required meeting both project-specific conditions (e.g., on Kyrgyz National Energy Holding Company achieving financial performance criteria) as well as a number of broader conditions, such as the adoption of national legislation regulating electricity and petroleum development, and the establishment of social safety nets (World Bank 2006).

Such conditions are also found in GEF project documents. Consider GEF Project 2903 implemented by the WB in Tanzania. ${ }^{3}$ The project is titled "Tanzania Energy Development and Access Project" and helps electrifying the countryside through sustainable energy, such as solar power. One of the conditions im-

\footnotetext{
${ }^{3}$ See http://www.thegef.org/gef/project_detail?projID=2903. Accessed on May 3, 2013.
} 
posed on project implementation is that the country must implement a financial restructuring of the national electricity company and appoint a competent management team to support the WB project.

While states shop for partner agencies, these agencies - similar to price discrimination in product markets - endogenously set their conditions on project funding. In this regard, our model is fully strategic. The partner agencies "price" their operations strategically, and recipient countries respond to these prices in their choice of a partner agency for any given project. Moreover, nothing prevents these partner agencies from refusing to implement projects - in the mechanics of the model, this amounts to demanding a prohibitively high price for project implementation. In general, the model is analogous to interactions between buyers (recipients) and sellers (implementing agencies) in imperfect markets.

We assume the different agencies can be ranked depending on their institutional resources, defined above as the combined value of their expertise and capital. The agencies are aware of their relative standing, and they set their conditions for projects accordingly. Those agencies that have limited resources must offer relatively generous terms to secure partners. They compensate for their relative lack of resources by partnering with states that are averse to strong conditionality. Stringent conditions on project implementation would leave the agencies without customers, as states would either choose more resourceful agencies offering similar terms, or perhaps not implement the project at all.

As to the incentives of the implementing agencies, we assume they are primarily interested in maximizing the resources they receive from the GEF and in imposing conditions on recipient countries. The first incentive resembles Tendler's (1975) notion that aid agencies face pressures to maximize the size of their portfolios. The second incentive is based on the assumption that the implementing agencies have policy interests, often stemming from the interests of the states that control the agencies (Nielson and Tierney 2003), that can be pursued through conditionalities (Dreher 2009; Kilby 2009; Stone 2008, 2011; Vreeland 2003). The implementing agencies choose the prices of implementation based on these premises. They are interested in expanding their project portfolios, provided that they receive a sufficiently high price for implementation.

At the same time, agencies with abundant resources can exploit their expertise to enhance their payoff from partnerships. They understand that states for whom successful project implementation is important will accept co-financing requirements and conditionalities. When an international agency has access to valuable 
resources that would benefit the recipient, it can offer these resources to the recipient's disposal in exchange for policy change (Dreher 2009; Kilby 2009; Stone 2011).

Given the resulting menu of alternatives, one may expect states to choose partners based on their own valuation of the project. Since some states place high value on successful project implementation in general, they are willing to make the trade-off between implementation cost and agency resources. Even if the project is costly and carries conditionalities, excellent implementation is valuable enough. Other states may consider some projects to be less important than others. In such cases, they turn to agencies that allow project implementation at a low cost.

\subsection{Model and Equilibrium}

Let there be three actors, one recipient, $r$, and two funding agencies, $f=A, B$. The payoffs for the recipient are defined as

$$
\Pi_{r}=b(t) q_{f}-p_{f}
$$

Here, $q_{f}$ is the agency $f$ 's resource level for project implementation, assumed to depend on resources (expertise and capital). The endogenous price that the agency charges for its services is denoted by $p_{f}$, and $b(t)$ is the recipient's valuation of the project, with $t \in\{L, H\}$. Project valuation is increasing in project type, $b(H)>b(L)$. Further, let $\tau_{t} \in(0,1)$ be the probability of type $t$, where $\tau_{H}=1-\tau_{L}$. Without loss of generality, we assume $q_{A}>q_{B}$ so that agency $A$ is better endowed than agency $B$.

The payoff for agency $f$ is

$$
\Pi_{f}=p_{f}-c_{f},
$$

where $c_{f} \geq 0$ is agency $f$ 's exogenous implementation cost. This payoff states that the agency maximizes the difference between the price and the implementation cost. The price could be allocated to the collective principal governing the agency. It could also benefit agency staff.

The agency selection game proceeds as follows:

(1) Each funding agency $f$ sets a price of project implementation, $p_{f} \geq 0$.

(2) The recipient type $\tau \in\{L, H\}$ is drawn by nature. 


\section{(3) Recipient $r$ selects a funding agency $f$.}

Note that the funding agencies set the cost of project implementation without information about the recipient's valuation of the project, high $(H)$ or low $(L)$. For example, the recipient's valuation of the project could depend on the context where the project is implemented, so that the recipient has more detailed information than the funding agency. The recipient, of course, observes its own type before moving and selects an implementing agency.

The game is solved by backward induction in the online appendix. In equilibrium, the more resourceful agency $A$ demands a higher price for project implementation, provided that the recipient ascribes a high value to the project with a sufficiently high probability. Intuitively, agency $A$ exploits its competitive advantage relative to agency $B$, thus capturing rents from the recipient. The recipient selects the more resourceful agency if and only if the recipient's valuation is high.

\subsection{Testable Hypotheses}

The theoretical association between project valuation and the equilibrium choice of agency is not itself a testable proposition. The second contribution of our theory is the development of three propositions regarding states' valuation of a given project. These propositions emphasize three specific influences, and by focusing on these covariates, we can test our hypotheses against project implementation data. While the model itself demonstrates the association between project valuation and the equilibrium choice of agency, the predictions are based on a more informal form of reasoning regarding the covariates of project valuation. In other words, the three factors analyzed below are assumed to increase the prior probability that $r$ ascribes a high value to project implementation, $t=H$. Through the endogenous competition mechanism characterized above, the recipient's project valuation shapes the likelihood that it chooses to work with more or less resourceful implementing agencies.

We focus on two different types of covariates. First, state characteristics may influence project valuation and agency choice. For a given type of project, we may expect some states to ascribe systematically higher valuation to successful implementation. Since our projects focus on public goods, standard theories of governance, such as the selectorate theory (Bueno de Mesquita et al. 2003) and economic theories of political competition (Stigler 1972; Wittman 1995), suggest that democratic states value successful project 
implementation more than do autocracies. Although democracies are also suffering from governance failures related to special interests (Truman 1951; Dahl 1967; Olson 1982; Grossman and Helpman 1994), their governments at least face electoral constraints to their behavior. In autocracies, special interests are also influential and the dictator's behavior is less constrained.

Here, we also make the assumption that the projects implemented by the agencies generate public goods for the population of the recipient country. Agricultural infrastructure projects would benefit large numbers of farmers in predominantly rural societies, forest conservation efforts would protect the livelihoods of large segments of the society dependent on forest products, and urban renewal projects would benefit the rapidly growing urban segments of the society.

In sum, we assume that the projects in focus generate national public goods, instead of direct private revenue that the ruler could distribute to elite constituencies along the lines suggested by Wintrobe (1998). While development projects also generate private benefits, such as employment, our theory focuses on projects that would not be implemented without external assistance. Consequently, the issue of aid fungibility is not a major factor.

We expect that democratic governments will be more interested in securing any given public good because democratic political institutions empower mass constituencies who benefit from the broad supply of public goods. Conversely, autocratic leaders are, given the modest political benefits of the project, in relative terms more worried about the cost of the conditionalities and policy changes that resourceful agencies require. Since the survival of autocratic leaders depends on the provision of private benefits to elite supporters (Bueno de Mesquita et al. 2003; Wintrobe 1998), they cannot afford to accept the policy changes that resourceful agencies require in exchange for project implementation.

From these considerations, we derive our first hypothesis. Compared to dictators, democratic governments value more the additional public goods that projects implemented by resourceful partner agencies generate. All else constant, democracies should ascribe a higher premium for finding resourceful implementing agencies.

Hypothesis 1 (democracy and agency choice). When planning projects, democracies are more likely to emphasize resources in agency selection than do autocracies. 
Implementing agencies may also themselves prefer democracies, because this regime type increases the recipient's incentive to invest in public goods. In this regard, the incentives of democratic recipients and implementing agencies can be complementary.

In addition to state characteristics, we expect project characteristics to influence agency choice. Inevitably, states value some projects more highly than others. We can further test our theory by examining how project type shapes states' decision to collaborate with resourceful but selective funding agencies. For instance, we expect project size to affect a state's willingness to pay for agency resources. We define project size in terms of the capital investment required, so that 'large' projects require a lot of capital while 'small' projects can be implemented with less.

Large projects not only produce more public goods than small projects, but the intricacies of implementing large projects are of a different magnitude than those of implementing a small project. States have stronger incentives to emphasize resources in the implementation of large projects because the difference in capital and expertise between funding agencies is more important when large projects are under consideration. Agency resources come handy in the implementation of complex projects that require substantial expertise and experience. Such projects present major challenges for international agencies that have limited experience and a small staff with specialized expertise on a narrow range of topics.

Hypothesis 2 (project size and agency choice). When planning projects, the likelihood that a country emphasizes resources in agency selection increases with project size.

Another project characteristic of interest concerns the nature and scope of the public goods that the project generates (Hicks et al. 2008). Some projects facilitate the provision of local public goods, such as waste treatment and the provision of clean drinking water. The benefits of these projects accrue mainly, if not entirely, within the borders of the recipient state. In contrast, other projects are designed to contribute to regional or global public goods such as conservation of biological diversity. While these projects may be located within a specific country, and may generate some local benefits, the primary purpose of such projects is to generate positive externalities. Given that a government's political survival depends first and foremost on the behavior of domestic constituencies, we expect that governments will be more likely to partner with selective but resourceful agencies when local public goods are at stake. Conversely, we expect 
that governments will prefer to lower implementation costs when designing projects that generate global public goods. Since projects for global public goods only generate national benefits as a side product - for example, Clémençon (2006) shows that climate projects generate private investment in renewable energy, thus improving energy access and security - the national government's interest in the project is at least somewhat smaller than in the case of projects that primarily focus on national public goods. We summarize these expectations in our third hypothesis.

Hypothesis 3 (project focus and agency choice). When planning projects, the likelihood that a country emphasizes resources in agency selection is higher for projects focusing on local than on global public goods.

Closely related, governments in developing countries may also implement global projects as an instrument of symbolic politics (Meyer et al. 1997). By doing so, they signal their goodwill to donors interested in such projects. Since symbolism does not depend on competent implementation, recipients can afford to instead rely on agencies that impose few conditions. If these agencies are members of the United Nations family, they would also be ideal for signaling goodwill and interest in global governance. If symbolic actions required resources, the recipients would instead have to go to resourceful organizations.

\section{Quantitative Analysis: Research Design}

We compiled a data set of all 2,882 bilateral GEF projects from 1991 to $2011 .{ }^{4}$ The main analysis only examines projects that were not rejected or canceled, but the online appendix shows that results are robust if the fewer than hundred failed projects are also included. This data set excludes projects for which a specific recipient is not identifiable; for example, projects on global or regional scales are excluded. Projects within the GEF Small Grants Program are also excluded because they are inappropriate for this study. Unlike conventional GEF projects, these are not designed and implemented with the consultation of an implementing agency; agency selection is not relevant to this process. Moreover, small grant projects are not negotiated by recipient governments. Rather, they are proposed by, and awarded directly to community organizations. The data set contains projects from several focal areas: biodiversity (1,073 projects, 37\%),

\footnotetext{
${ }^{4}$ This database is available online at http://www. gefonline.org.
} 
climate change (912 projects, 32\%), ozone depletion (28 projects, $1 \%$ ), international waters (191 projects, $7 \%$ ), land degradation (97 projects, $3 \%$ ), and persistent organic pollutants (225 projects, $8 \%$ ).

The GEF is ideal for our purposes because, as we described earlier, the GEF delegates substantial authority to its implementing agencies. While the GEF Council sets the broad guidelines of the organization's operations and decides on general allocation principles, the practical work is done by implementing agencies. These agencies - the World Bank, several UN agencies, and a number of regional development banks - are not only responsible for implementing GEF projects, they also work with recipient government representatives to design project proposals for GEF consideration. One consequence of this, according to a former GEF CEO that we interviewed, is a strong competitive dynamic among GEF agencies, as each tries to maximize its share of GEF project funds in a given year (Barbut 2012). Thus, the GEF provides us with an ongoing example of forum shopping, involving a diverse set of organizations.

The GEF project cycle is described in full in the online appendix. To summarize, a project begins when the recipient country, working through a designated national GEF focal point, finds a suitable project. It collaborates with one of the implementing agencies, chosen by the recipient country, to prepare a project identification form. The form details the project, requests funding from the GEF, and summarizes the availability of co-financing. While the recipient is ultimately responsible for selecting projects, the implementing agency can use the negotiations on the form to impose conditions on implementation. Next, the project is evaluated by the GEF and sent for approval by the GEF Council. If approved, the project funds are disbursed and implementation, followed by a review, begins.

In assuming that recipient countries can shop among multiple implementing agencies, we do not argue that implementing agencies themselves would not advertise or market their services. Organizations such as the WB have permanent field offices in many recipient countries, and these offices are continuously proposing ideas to these countries. At the same time, the ultimate authority to initiate a GEF project always lies with the recipient country. Our model captures the interaction between implementing agencies and recipient countries by allowing the implementing agencies to set the prices of implementing GEF projects and allowing the recipient countries to choose among the available offers. For example, both the WB and UNDP could propose energy conservation projects to the Government of India. Based on the proposals, the government could then propose to the GEF that a project be implemented with one of the partners. 
The GEF implementing agencies impose two kinds of conditions on project implementation. First, they require co-financing by the government and other actors, such as the private sector and non-governmental organizations. This is the most common requirement, with the GEF's average contribution being only $36 \%$ in WB and $60 \%$ in non-WB projects. Second, the agencies impose conditions on project implementation to maximize environmental effectiveness. These conditions are hard to quantify, but GEF documents frequently state that the project must be implemented in a certain fashion, limiting the recipient's freedom to maneuver.

\subsection{Dependent Variable}

The outcome of interest is if a recipient government has chosen to emphasize institutional resources in selecting which GEF agencies to partner with. Among the various GEF agencies, the WB stands out by offering the most institutional experience in implementing development projects, the most experience in implementing large projects, and the largest professional staff. In noting the WB's advantages in institutional resources, it is not necessary to make the dubious claim that other GEF agencies, such as the United Nations Industrial Development Programme (UNIDO), are qualitatively incompetent. Rather, we simply observe that no other GEF agency has access to the same range of institutional resources as does the WB. Our dependent variable, then, captures whether a country has chosen to partner with the WB for the purpose of obtaining project financing from the GEF. We do this by creating a dichotomous variable, set to 1 if the implementing agency is the $\mathrm{WB}$, and to 0 otherwise.

Indeed, the GEF itself observes that different implementing agencies offer different comparative advantages. Interestingly, while the GEF differentiates among its various focal areas, there is very little variation in agencies' comparative advantages across issue areas. Rather, the different agencies' comparative advantages are driven mainly by the "type of policy intervention" of a given project. The GEF observes that the World Bank has a comparative advantage in investment across all focal areas, with the regional development banks providing secondary options. In contrast, the UNDP has a comparative advantage in the provision of technical assistance across all focal areas. Finally, the GEF finds that UNEP offers comparative advantages in a variety of areas, such as standard setting, monitoring, and norm promotion (GEF 2007). This shows that while different agencies have different core competencies, for the evaluation of investment projects, it 
suffices to distinguish between WB and other agencies. ${ }^{5}$

The GEF values a number of different types of institutional resources, based on the type of policy intervention. However, this does not mean that recipients assign the same value to each type of policy intervention. Our theory of agency choice suggests that recipients will place the greatest value on policies that affect them directly. In the case of the GEF, recipients will value investment projects more than, for example, provision of technical advice or assistance in setting standards.

There are many other differences between the WB and other implementing agencies. Most importantly, the voting structure of the WB is different from the voting structure of the United Nations bodies. However, we are not aware of any theoretical accounts of these other differences that would generate the exact three hypotheses we have developed above. For example, it is not clear at all why the WB's voting structure should favor large projects. Similarly, there does not appear to be a plausible association between the type of public goods (local or global) and voting rules. Given this, we are confident that our distinction between the WB and the other agencies is a plausible proxy for the underlying interest in resources, defined as capital and expertise.

One caveat to our analysis pertains to regional development banks. In regard to capital and expertise, they are similar to the WB in that they also have experience in funding major development projects. At the same time, their portfolios and total resources are much smaller than those of the WB. Therefore, we have chosen to treat them as less resourceful than the WB. There are fewer than a hundred projects implemented by regional development banks, and assigning the value of 1 to these projects, as though they were implemented by the WB, has virtually no effect on our findings.

There is also possible selection bias since failed (rejected or canceled) project proposals are not included in the data. The appendix repeats the analysis with such projects included in the data set, and the results remain virtually unchanged. While this does not account for potential projects that were never proposed, the evidence does not suggest a selection bias in the results.

\footnotetext{
${ }^{5}$ Occasionally an additional agency is assigned to assist implementation. The GEF's description of comparative advantages suggests that policy intervention is important in selecting a primary agency; focal area expertise, where it exists, is listed second.
} 


\subsection{Independent Variables}

Our first hypothesis is that democracies will be more likely than autocracies to prioritize resources over project costs in selecting GEF agencies. Accordingly, our first explanatory variable is recipient government type. We use a binary measure (Cheibub, Gandhi, and Vreeland 2010), set to 1 if the recipient government was democratic in a given year, and otherwise 0, where democracy refers to the existence of free and competitive elections that determine the national leader's identity.

The second hypothesis is that successful implementation of large projects will be particularly important to recipient countries. Accordingly, recipients will be increasingly likely to pay for institutional resources as project size increases. Our second independent variable, then, is project size. Rather than identifying "large" projects by fixing an arbitrary threshold, we simply use total project value, as listed in the GEF project database. To mitigate the influence of outliers, we logarithmize these values. As the descriptive statistics in the appendix show, there is remarkable variation in the size of environmental projects funded under the GEF.

Our third hypothesis is that recipients will assign greater value to projects that provide local public goods than those that provide global public goods. Accordingly, to assess our third hypothesis, we need to know whether the benefits of a given project are largely internal or external to the recipient. To do this, we leverage environmental impact coding from the newly-published AidData environmental project database. ${ }^{6}$ Specifically, we matched projects from the GEF database to projects in AidData Environment, allowing us to use the brown/green measure in AidData Environment. Projects that are designed to generate positive externalities are coded "green," while projects that deliver primarily local benefits are coded "brown." Using these data, we constructed a binary indicator set to 1 if a project was coded green, and 0 otherwise. ${ }^{7}$

To illustrate the coding, consider the following examples:

- Desertification, carbon dioxide emissions, and family planning projects are coded as "green" because they are directly relevant to global environmental projects.

- Drought control, solid waste treatment, and soil fertility projects are coded as "brown" because their

\footnotetext{
${ }^{6}$ Available online at http://www. aiddata.org/content/index/Research/research-datasets.

${ }^{7}$ In terms of AidData Environment, our indicator is set to 1 if a project is coded either "environmental strictly defined - green" or "environmental broadly defined - green." Our indicator is set to 0 if a project is coded "environmental strictly defined - brown," "environmental broadly defined - brown," "neutral," "dirty strictly defined," or "dirty broadly defined."
} 
direct relevance is limited to the national level.

Importantly, this coding also highlights our argument above that the brown-green distinction is never absolute. Green projects, such as measures to combat desertification, also produce local benefits. Some brown projects, such as solid waste treatment, may produce global benefits, such as reduced greenhouse gas emissions. In the data, the brown-green distinction made by AidData researchers is based on the primary benefits of each project.

While it is true that the GEF was established for the purpose of financing global environmental goods, it is also the case that the GEF funds a range of projects, varying widely in scope. Many projects that fall in "global" environmental sectors, nevertheless provide benefits that accrue most directly to the recipient. For example, GEF Project \#32 financed the construction of small hydro power plants in Macedonia. For purposes of GEF governance, this project fell under the sectoral category of "climate change." However, the more fine-grained coding of AidData-Environment characterizes this project as "broadly environmental," with project benefits accruing mainly to the recipient. Accordingly, this "climate" project is coded "brown."

\subsection{Control Variables}

We present several models, with a variety of different control variables. First we control for the logarithm of per capita income in recipient countries, obtained from the World Development Indicators. Our theory focuses on recipient willingness to pay for institutional resources; it is also possible that ability to pay influences agency selection. Conversely, funding agencies themselves may have demand for working with certain types of recipients in particular (Dreher, Sturm, and Vreeland 2009). In both cases, we would expect higher income recipients to be relatively more likely to partner with the WB.

Recipient population also may influence agency selection, particularly if certain types of agencies place particular value on working in large countries (Stone 2011). As with income, we obtain this information from the World Development Indicators. It is logarithmized to reduce the influence of outliers.

Next, from the International Country Risk Guide (ICRG), we add controls for corruption and investment climate. To the extent that corrupt governments may place added value on simply receiving project funding, as opposed to implementation success, corruption may influence agency selection. Similarly, a country's investment profile may influence the level of conditions that agencies attach to projects, thereby influencing 
the "price" of institutional resources and, thus, agency selection. Note that the ICRG scales these variables such that higher values are more favorable; higher scores thus denote less corruption and a more favorable investment climate.

The extent to which recipients have established a working relationship with the WB may also affect project conditions and the likelihood that a recipient will partner with the WB in the future. To account for such path dependence, we control for the cumulative number of WB projects in a recipient country at the time of GEF project design.

Other variables that may influence the "price" of working with the WB are recipient membership on the WB Executive Board (Kaja and Werker 2010) and rotating membership on the United Nations Security Council (Dreher, Sturm, and Vreeland 2009). We add dummy variables for each of these, set to 1 if the recipient country was a member of the WBEB or UNSC at the time of GEF project design.

Finally, we use a series of regional dummy variables to control for possible regional influences and include cubic time polynomials to keep serial correlation at bay (Carter and Signorino 2010). We follow the WB coding scheme for classifying recipient country location.

Summary statistics and graphical illustrations of the distributions in the data can be found in the supplementary appendix.

\subsection{Model Specification}

The outcome of interest in our empirical model is whether or not a recipient has chosen to partner with the WB to implement a given GEF project. Since our dependent variable is a binary measure, we use a binary probit specification to model the underlying propensity to choose the WB as a partner agency. Thus, our basic model is:

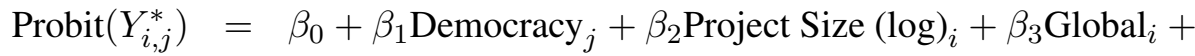

$$
\begin{aligned}
& \gamma \text { Controls }_{i}+\delta \text { Controls }_{j}+t+t^{2}+t^{3}+\epsilon_{i, j} .
\end{aligned}
$$

Here, $Y_{i, j}^{*}$ represents the probability of a project $i$ in country $j$ being implemented by the WB, given relevant explanatory variables and controls. $\beta_{1}$ is the coefficient for status as a democracy, $\beta_{2}$ is the coefficient for the 
logarithmized total project cost, $\beta_{3}$ is the coefficient for project scope. $\gamma$ and $\delta$ are vectors of coefficients for project- and country-level control variables, respectively, including region fixed effects. $\beta_{0}$ and $\epsilon$ denote the intercept and the error term, respectively, while $t, t^{2}$, and $t^{3}$ are linear, quadratic, and cubic time variables to capture temporal dependence.

We cluster standard errors by country $j$ because observations may be correlated within countries. This is a near certainty given the context in which GEF projects are designed. Recipient country representatives are likely to develop experience over time with one or more GEF agencies. Moreover, recipient governments are very likely to have pre-existing, outside relationships with one or more of the organizations that serve as GEF agencies. ${ }^{8}$

More complex models of bilateral cooperation, which specifically model the participation incentives of both sides, exist (Stone 2008). Given that our theory focuses on the recipient side, we opt for a simple model that focuses on the recipient's decision. A bilateral model would be warranted if we had detailed expectations for the incentives of different implementing agencies with respect to different recipients and projects, as well as the empirical data to operationalize these expectations. Since neither condition is met, a simple and easily interpretable binary probit specification seems more appropriate. The findings from this analysis lay the foundation for future research that offers a more nuanced account of the supply side.

\section{Quantitative Analysis: Findings}

Table 1 shows the estimation results for nine models. Model (1) is the most minimal specification, with only the three explanatory variables of interest along with a cubic time polynomial. Models (2) through (5) introduce progressively larger sets of control variables, including regional indicators. Model (6) excludes projects from the GEF pilot, during which the GEF was governed substantially by the WB. Model (7) excludes projects after 2006, when the GEF adopted the Resource Allocation Framework (RAF), which provides formal allocation criteria that influence recipients' leeway in bargaining with the GEF and its agencies. ${ }^{9}$ Model (8) excludes "enabling activities," defined as projects related to one of the multilateral treaties

\footnotetext{
${ }^{8}$ In checking the robustness of our results, we also estimate random effects probit regressions. Our findings are robust to this specification; we present complete results in the online appendix.

${ }^{9}$ As Figure 1 shows, while partnering with the UNDP has been consistently less costly than cooperating with the WB, the difference shrank somewhat following the GEF's adoption of the RAF.
} 
for which the GEF serves as the primary financing mechanism. Finally, model (9) excludes multifocal projects. Although the AidData Environment database provides coding for the primary scope of benefits for all environmental projects, codes are less certain for projects that serve multiple focal areas (356 projects, $12 \%)$ because they may generate several primary benefits.

The results support the agency selection model. We find strong evidence that the WB is less likely to be chosen as the lead implementation agency for global public good projects. Across all nine models, the global public good coefficient is negative and statistically significant at $p<0.01$. Likewise, we find that the project cost coefficient is positive and strongly significant across all nine models. Finally, we find that democracy generally has a positive effect on WB selection. In models (1)-(4) and (9), the democracy coefficient is significant at $p<0.05$. In models (5) and (6), the democracy coefficient remains broadly similar in sign and magnitude, though significance falls to $p<0.10$, likely because of the smaller sample sizes of these models. The sign of the coefficient is positive in model (8), though statistical significance is not reached. The only model that has a negative coefficient is (7), and here the coefficient is tiny, with a standard error almost 40 times its size. Overall, the evidence supports our hypotheses.

Regarding our control variables, we generally observe inconsistent or insignificant results, with three exceptions. We find a negative relationship between recipient income and WB selection. This relationship is likely driven on the Bank's side, reflecting a preference for promoting development in addition to funding the provision of environmental goods. We find that the extent to which a recipient has developed a working relationship with the Bank, which is measured as the cumulative number of WB projects in a country, has a positive effect on World Bank selection. Finally, we find a significant negative relationship between UNSC rotating membership and World Bank selection. At first glance, this seems surprising; we expected that UNSC membership might be a source of recipient leverage. However, the decision not to partner with the WB is functionally equivalent to the decision to partner with an UN agency. In hindsight, it is unsurprising that rotating UNSC members are more likely to choose UN partner agencies.

[Table 1 about here.]

To shed light on the substantive effect of each of these variables, we simulated one thousand draws from a multivariate normal distribution from model (1) in Table 1 above (King, Tomz, and Wittenberg 2000), in an effort to estimate the change in predicted probability of WB choice following changes from local to global 
project scope, from autocracy to democracy, and from mean project cost to one standard deviation above the mean. When not used as a change variable, project scope and democracy were held at their median values; project cost was held at the mean value. For all three independent variables, we held the time polynomial at the mean value. Figure 2 plots the first difference in predicted probabilities of WB choice for each of the simulated changes described above. Ceteris paribus, we find that changing to a global scope reduces the probability of WB choice by roughly 20 percentage points. Conversely, a one standard deviation increase in project cost increases the probability of World Bank selection by roughly 25 percentage points. In contrast, we find weaker results for government type. Though the change from autocracy to democracy is significant, as the 95 percent confidence interval does not overlap zero, the change in predicted probability of World Bank selection is only 5 percentage points.

[Figure 2 about here.]

While agency selection may be influenced by a wider range of variables than we discuss here, the changes in predicted probability shown in Figure 2 indicate that the propositions derived from our theoretical model are quite powerful. An autocratic country, faced with the prospect of obtaining funding for a small to medium climate project is quite unlikely to choose to partner with the WB. In contrast, democratic recipients that are interested in providing major local or national public goods are substantially more likely to choose the WB, compared to an "average project, average recipient" baseline.

Next, we offer a more nuanced analysis of the effect of project size on the choice of WB as an implementing partner. Though there is a strong relationship between project size and agency choice, it is not deterministic. In other words, the GEF does not direct all large projects through the WB, and all smaller projects through UN agencies. The WB has implemented a number of relatively small projects, and nonBank agencies have implemented several large projects. GEF projects implemented by the World Bank range in (logged) project cost from 9.5 to 21.0, with a mean of 16.3. GEF projects implemented by nonBank agencies range in (logged) project cost from 8.9 to 19.6, with a mean of 13.9. Figure 3 shows how the predicted probability of World Bank selection changes across the observed range of values of project cost.

[Figure 3 about here.]

As to robustness, we implemented several tests. First, we test different model specifications. More 
specifically, we estimate our models with project fixed effects included to control for project-specific effects that our other control variables do not capture. We also implement a random effects model to account for the panel nature of the data, with virtually no change in the results. For a country-level analysis, we aggregate our data at the country level and estimate a standard least squares model with shares of WB projects as the dependent variable. ${ }^{10}$ Second, we allowed our independent variables to interact with each other. Based on Wald tests for the statistical significance of interaction effects (Ai and Norton 2003; Brambor, Clark, and Golder 2006), the only statistically significant interaction was between the indicator for global public good and project cost. With a positive sign, the coefficient suggests that the negative effect of global public goods on the probability of WB selection is diminished for large projects. ${ }^{11}$ Finally, we found that results remain unchanged, no matter if we include canceled or rejected project proposals in the data or if we exclude enabling activity projects.

To summarize, our three primary explanatory variables shape the likelihood that a recipient chooses to collaborate with the WB on GEF projects. Democratic recipients work more closely with the WB, and a given recipient is more likely to select the WB if the project is large and/or provides national instead of global public goods. These patterns are consistent with our theory of agency choice.

\section{Causal Mechanisms: Qualitative Analysis}

We now turn to qualitative methods for another test of the theory. We interviewed the country focal points of as many major GEF recipients as possible. Overall, we tried to interview 23 focal points and received a response from four: Brazil, Burkina Faso, Mexico, and South Africa. The interview questionnaire was designed to illuminate causal mechanisms and the relative role of supply and demand factors. To summarize the results, we found that both the implementing agency and the recipient play an active role in project negotiations. However, the recipient is generally more active in project initiation, as our theory suggests. Equally important, we found no evidence that the different implementing agencies would discriminate against recipients or projects based on their characteristics. This finding goes against some plausible

\footnotetext{
${ }^{10}$ We estimate both standard OLS and weighted regressions modeling each country's variance as the inverse of the number of GEF projects. Both robustness tests validate the hypothesis.

${ }^{11}$ Multiplicative interaction effects are not necessarily needed in non-linear models to account for non-linear effects. As suggested by Berry, DeMeritt, and Esarey (2010) we implemented likelihood ratio tests to check if the inclusion of interaction effects is warranted. Further details can be found in the supplementary appendix.
} 
alternative explanations to our theory.

\subsection{Research Design}

The questions were sent to the most important GEF recipients according to the number of projects implemented during the 1991-2011 period. We focused on major recipients due to their substantive importance and the high likelihood of receiving a response. The interview questionnaire contained seven questions on project implementation. ${ }^{12}$ The questions focused on the role of the implementing agency and the recipient country government in project initiation (Q1 and Q2), the possibility that the WB and UN agencies have different strengths (Q3 and Q4), the role of project size (Q5), considerations around climate change mitigation (Q6), and the possibility that the WB is more incriminating in project selection than other agencies (Q7). The questions were formulated such that they did not lead the respondents, and we did not reveal our hypotheses to the respondents. Since all respondents were guaranteed anonymity, we do not discuss the strategies of specific countries below. Instead, we provide an overview of the responses.

\subsection{Findings}

Most importantly, responses to questions Q1 and Q2 on project initiation showed that the host country plays an active and leading role in project initiation. Of the four countries, only South Africa indicated that the implementing agencies play a role in proposing projects. The three other countries instead suggested that planning for GEF projects is based on national plans more generally, and these are prepared without the direct participation of the implementing agencies.

Based on questions Q3 and Q4, asking about relative strengths of the WB and UN agencies, the WB's advantage in the implementation of large projects became clear. Brazil and Mexico emphasized that the WB is better suited for the implementation of large and/or technically complex projects, and Mexico also noted that the UN agencies are more flexible in the implementation of small projects. Burkina Faso stated that they have a strong historical relationship with the UNDP, and all four respondents claimed that different implementing agencies have different thematic emphases.

Question Q5 focused on project size in particular. Of the four respondents, Brazil and Mexico indicated

\footnotetext{
${ }^{12}$ The interview questionnaire and additional details on the interview process can be found in the online appendix.
} 
that the WB expresses interest in large projects, while the UN agencies are more willing to implement for small projects. Notably, these were the same respondents that also emphasized the advantages that the WB has in the implementation of large projects already in the prior question.

There was no evidence in responses to question Q6 that climate change projects would somehow differ from others. All four countries indicated that climate change projects are planned and implemented similar to projects under other priority areas. For example, Burkina Faso emphasized that the rules for project implementation are set by the GEF, and climate change projects follow those rules without deviations.

Finally, there was mixed evidence for the claim that the implementing agencies have their own preferences. Brazil did not see evidence of such claims, while Burkina Faso emphasized thematic differentiation. Mexico argued that the WB is interested in large projects. South Africa said that the WB has its own preferences, but did not elaborate on what these preferences are.

\section{Alternative Explanations}

It remains to consider the possibility that the correlations should instead be attributed to agency characteristics without consideration of recipient incentives. The theory emphasizes the interactive effects of demand and supply, whereas an alternative explanation would focus exclusively on the supply side. In particular, two important concerns are worth raising. First, it could be that the WB itself favors democracies simply because it is controlled by democratic donors. To test this argument, we used our WBEB variable to compute the share of democratic members on the Board in a given year. Since the variable is not normally distributed, we constructed an indicator for whether the number of democracies was above or below the mean $(0.73)$ in the sample in that year. We interacted this variable with the democracy indicator to see if the Bank's preferences condition the role of democracy. If the Bank's preference for democracy were decisive, then the interaction term should be positive and statistically significant, as democratic recipients would be particularly favored when the Board is dominated by democracies. The results of this test as well as two additional robustness checks, including the count and share of democratic countries serving on the WBEB, are reported in the supplementary appendix. All clearly reject the alternative hypothesis.

Second, project size could induce countries to choose the WB as a partner simply because the other agencies cannot implement the largest projects in the data set. To test this hypothesis, we re-estimated the 
models without all projects considered "large" by the GEF. This is a hard test of our theory because only small and medium-sized projects are left. For brevity, the results, which are similar to the main results, are again reported in the appendix. The coefficients of the three key variables are always into the right direction and mostly statistically significant; moreover, the substantive effects for the same changes as described above are also similar in size. ${ }^{13}$

\section{Conclusion}

International cooperation occurs in a densely populated institutional environment. Neither states nor organizations hold all the cards in this process. We contribute to the literature on forum shopping in international relations by arguing that one of the main criteria differentiating organizations that operate in a given issue space is institutional resources. Absent such differentiation, one would expect institutional diversity to lead to competition among international organizations, giving states power to dictate the terms of collaboration with the former. In reality, however, international organizations are differentiated. In the fields of development assistance and environmental finance, the recognition that a given funding agency possesses advantages in institutional resources may weaken a state's outside options. This, in turn, provides funding agencies greater leverage to negotiate terms of cooperation.

We explore this dynamic by developing a theory of collaboration between states and international agencies. We argue that the various agencies that implement GEF projects are differentiated in institutional resources. Our model suggests that a state's willingness to pay for institutional resources is driven both by recipient characteristics and project characteristics. The model endogenizes not only the state's incentive to select the implementing agency, but also the implementing agency's incentive to impose conditions on project implementation. In this regard, the theory is fully strategic and accounts for the incentives of both the donor and the recipient.

The empirical findings from an analysis of the universe of GEF projects during the 1991-2011 period

\footnotetext{
${ }^{13}$ For 1,000 draws from a multivariate normal based on model (1), we find a mean effect of -9 percentage points ( -3 and 14 percentage points as lower and upper confidence bounds, respectively) for a change from local to global public goods. The mean effect for increases in total project costs by one standard deviation above the mean is 17 percentage points, with 12 and 23 percentage points as the lower and upper end of the $95 \%$ confidence interval. The substantive effects for a change from an autocratic to a democratic regime type are weakest in absolute value, with an average increase of only 4 percentage points and a confidence interval ranging from 1 to 8 percentage points.
} 
support our hypotheses. Democratically governed countries place greater value on institutional resources due to their need to provide public goods to broad constituencies. Additionally, states value institutional competence more as stakes increase, due to an increase in project size. Finally, states value institutional resources when they expect to be the sole recipient of project benefits. Our analysis of GEF agency selection provided support to each of these hypotheses, as the central explanatory variables have large effects on the probability that a given state collaborates with the WB on any given environmental project. Qualitative evidence shows that the effect stems from interactions of the supply of and demand for agency resources, suggesting that theories focusing exclusively on supply or demand at the expense of the other are not sufficient to explain state-agency partnerships in project implementation.

These findings highlight the fact that recipient countries value local environmental goods and global environmental goods differently. To the extent that international finance for the provision of global environmental goods reflects donor interests at the expense of recipients, our findings have potentially troubling implications. It may be unrealistic to expect that institutions designed to promote development will be able to promote global environmental goods with the same effectiveness. A promising avenue for further research will be to examine the extent to which donors act on this knowledge in choosing which international agencies to deliver environmental financing to, which is itself an act of institutional choice.

The results also open avenues for future research. Our focus on project implementation is both substantive important and empirically convenient, but there are many other forms of collaboration between states and international organizations. One potentially interesting question for future research is the generalizability of our findings to other issue areas. For example, can states look for partners among multiple agencies when cooperation does not focus on specific projects, but instead focuses on the development of national policies? Similarly, are our findings applicable in areas of development assistance where the distinction between global and national public goods is less clear, such as public health? Our study offers a point of departure for the analysis of these questions. 


\section{References}

Ai, Chunrong, and Edward C. Norton. 2003. "Interaction Terms in Logit and Probit Models." Economics Letters 80 (1): 123-129.

Barbut, Monique. 2012. "Telephone Interview with the CEO of the Global Environment Facility." September 2012.

Barrett, Scott. 2003. Environment and Statecraft: The Strategy of Environmental Treaty-Making. Oxford: Oxford University Press.

Bayer, Patrick, Christopher Marcoux, and Johannes Urpelainen. 2013. "Leveraging Private Capital for Climate Mitigation: Evidence from the Clean Development Mechanism." Ecological Economics 96: 1424.

Berry, William D., Jacqueline H. R. DeMeritt, and Justin Esarey. 2010. "Testing for Interaction in Binary Logit and Probit Models: Is a Product Term Essential?" American Journal of Political Science 54 (1): 248-266.

Brambor, Thomas, William Roberts Clark, and Matt Golder. 2006. "Understanding Interaction Models: Improving Empirical Analyses." Political Analysis 14 (1): 63-82.

Bueno de Mesquita, Bruce, Alastair Smith, Randolph M. Siverson, and James D. Morrow. 2003. The Logic of Political Survival. Cambridge: MIT Press.

Busch, Marc L. 2007. "Overlapping Institutions, Forum Shopping, and Dispute Settlement in International Trade.” International Organization 61 (4): 735-761.

Carter, David, B., and Curtis S. Signorino. 2010. "Back to the Future: Modeling Time Dependence in Binary Data." Political Analysis 18 (3): 271-292.

Cheibub, José Antonio, Jennifer Gandhi, and James Raymond Vreeland. 2010. "Democracy and Dictatorship Revisited." Public Choice 143 (1-2): 67-101.

Clémençon, Raymond. 2006. "What Future for the Global Environment Facility?" Journal of Environment and Development 15 (1): 50-74.

Dahl, Robert A. 1967. Pluralist Democracy in the United States: Conflict and Consent. Chicago: Rand McNally.

Dreher, Axel. 2009. "IMF Conditionality: Theory and Evidence.” Public Choice 141 (1-2): 233-267.

Dreher, Axel, Jan-Egbert Sturm, and James Raymond Vreeland. 2009. "Development Aid and International Politics: Does membership on the UN Security Council influence World Bank Decisions?" Journal of Development Economics 88 (1): 1-18.

Fleck, Robert K., and Christopher Kilby. 2006. "World Bank Independence: A Model and Statistical Analysis of US Influence.” Review of Development Economics 10 (2): 224-240.

GEF. 2007. "Comparative Advantages of the GEF Agencies." Accessed September 30, 2012.

URL: http://www. thegef.org/gef/node/427 
Grossman, Gene M., and Elhanan Helpman. 1994. "Protection for Sale." American Economic Review 84 (4): 833-850.

Helfer, Laurence R. 2004. "Regime Shifting: The TRIPs Agreement and New Dynamics of International Intellectual Property Lawmaking." Yale Journal of International Law 29: 1-83.

Hicks, Robert L., Bradley C. Parks, J. Timmons Roberts, and Michael J. Tierney. 2008. Greening Aid? Understanding the Environmental Impact of Development Assistance. New York: Oxford University Press.

Hofmann, Stéphanie C. 2011. "Why Institutional Overlap Matters: CSDP in the European Security Architecture." Journal of Common Market Studies 49 (1): 101-120.

Humphrey, Chris, and Katharina Michaelowa. 2013. "Shopping for Development: Multilateral Lending, Shareholder Composition and Borrower Preferences." 44: 142-155.

Johnson, Tana, and Johannes Urpelainen. 2012. "A Strategic Theory of Regime Integration and Separation." International Organization 66 (4): 645-677.

Jupille, Joseph, and Duncan Snidal. 2006. "The Choice of International Institutions: Cooperation, Alternatives and Strategies." Working Paper, University of Colorado at Boulder and University of Chicago.

Jupille, Joseph, Walter Mattli, and Duncan Snidal. 2013. Institutional Choice in Global Commerce. New York: Cambridge University Press.

Kaja, Ashwin, and Eric Werker. 2010. "Corporate Governance at the World Bank and the Dilemma of Global Governance.” World Bank Economic Review 24 (2): 171-198.

Keohane, Robert O., and David G. Victor. 2011. “The Regime Complex for Climate Change.” Perspectives on Politics 9 (1): 7-23.

Kilby, Christopher. 2009. "The Political Economy of Conditionality: An Empirical Analysis of World Bank Loan Disbursements.” Journal of Development Economics 89 (1): 51-61.

King, Gary, Michael Tomz, and Jason Wittenberg. 2000. "Making the Most of Statistical Analyses: Improving Interpretation and Presentation." American Journal of Political Science 44 (2): 341-355.

Lyne, Mona M., Daniel L. Nielson, and Michael J. Tierney. 2009. "Controlling Coalitions: Social Lending at the Multilateral Development Banks." Review of International Organizations 4 (4): 407-433.

Meyer, John W., John Boli, George M. Thomas, and Francisco O. Ramirez. 1997. "World Society and the Nation-State." American Journal of Sociology 103 (1): 144-181.

Milner, Helen V. 2006. "Why Multilateralism? Foreign Aid and Domestic Principal-Agent Problems." In Delegation and Agency in International Organizations, ed. Darren G. Hawkins, David A. Lake, Daniel L. Nielson, and Michael J. Tierney. New York: Cambridge University Press.

Nielson, Daniel L., and Michael J. Tierney. 2003. "Delegation to International Organizations: Agency Theory and World Bank Environmental Reform.” International Organization 57 (2): 241-276.

Olson, Mancur. 1982. The Rise and Decline of Nations: Economic Growth, Stagflation, and Social Rigidities. New Haven: Yale University Press. 
Pevehouse, Jon, Timothy Nordstrom, and Kevin Warnke. 2004. "The Correlates of War 2 International Governmental Organizations Data Version 2.0." Conflict Management and Peace Science 21 (2): 101119.

Rodrik, Dani. 1995. "Why Is There Multilateral Lending?” NBER Working Paper 5160.

Sharma, Shalendra D. 1996. "Building Effective International Environmental Regimes: The Case of the Global Environment Facility." Journal of Environment and Development 5 (1): 73-86.

Stigler, George J. 1972. "Economic Competition and Political Competition.” Public Choice 13 (1): 91-106.

Stone, Randall W. 2008. “The Scope of IMF Conditionality.” International Organization 62 (4): 589-620.

Stone, Randall W. 2011. Controlling Institutions: International Organizations and the Global Economy. New York: Cambridge University Press.

Sykes, Alan O. 2008. “Transnational Forum Shopping as a Trade and Investment Issue." Journal of Legal Studies 37 (2): 339-378.

Tendler, Judith. 1975. Inside Foreign Aid. Baltimore: Johns Hopkins University Press.

Truman, David. 1951. The Governmental Process: Political Interests and Public Opinion. New York: Knopf.

Vreeland, James R. 2003. The IMF and Economic Development. New York: Cambridge University Press.

Winters, Matthew S. 2010. "Choosing to Target: What Types of Countries Get Different Types of World Bank Projects.” World Politics 62 (3): 422-458.

Wintrobe, Ronald. 1998. The Political Economy of Dictatorship. New York: Cambridge University Press.

Wittman, Donald A. 1995. The Myth of Democratic Failure: Why Political Institutions are Efficient. Chicago: University of Chicago Press.

World Bank. 2006. "Policy Conditions in World Bank Investment Lending." Operations Policy and Country Services. Accessed September 30, 2012.

URL: http://www-wds.worldbank.org/external/default/WDSContentServer/ IW3P/IB/2006/08/03/000090341_20060803094631/Rendered/PDF/36924.pdf 


\section{Mean GEF Funding Share in WB and UNDP Projects}

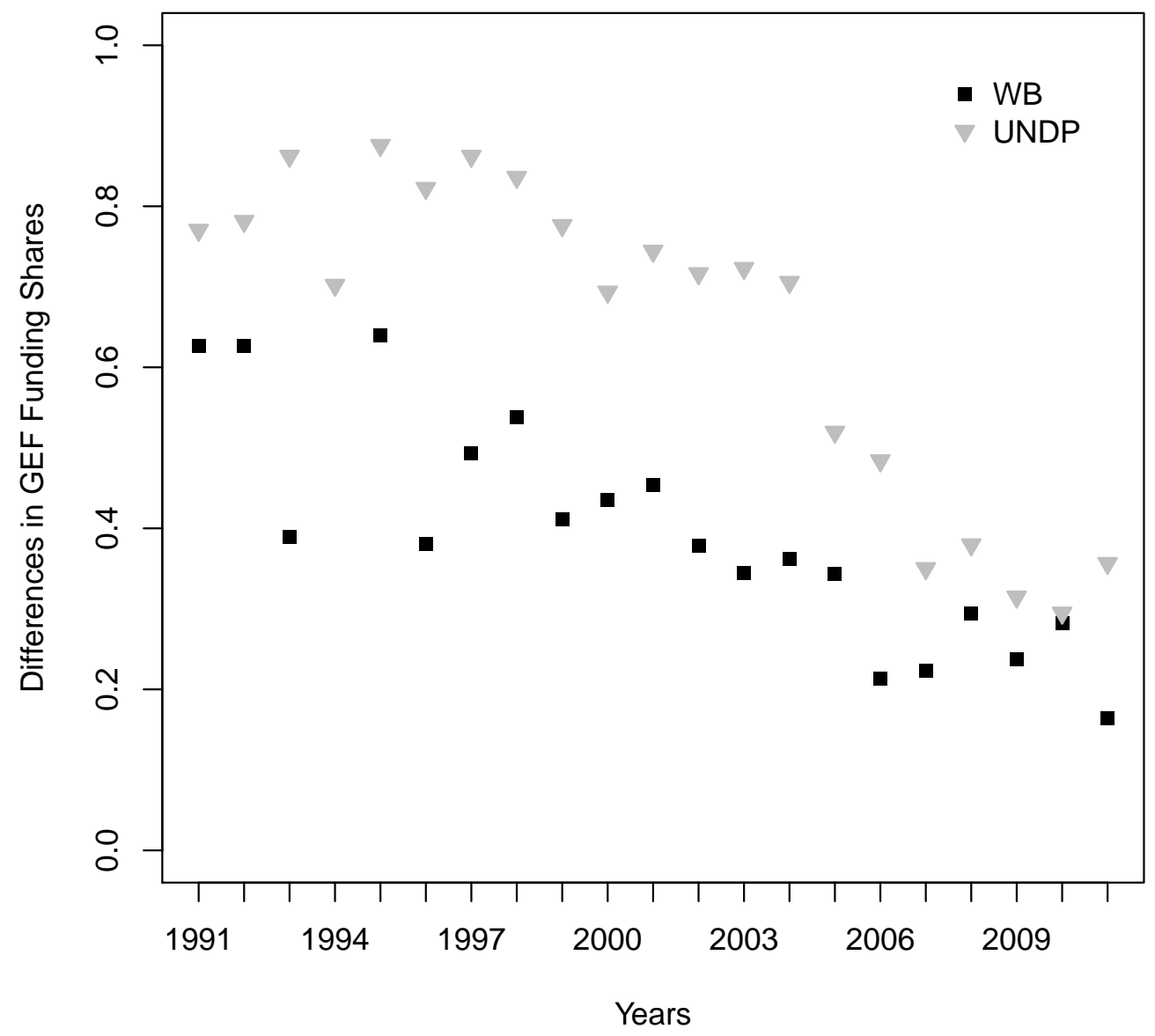

Figure 1: Mean GEF funding shares in WB and UNDP projects over the years 1991 to 2011. Black squares denote mean project contributions by the GEF in projects implemented through the WB, while gray triangles denote GEF funding shares in UNDP projects. 


\section{First Differences in Predicted Probabilities}

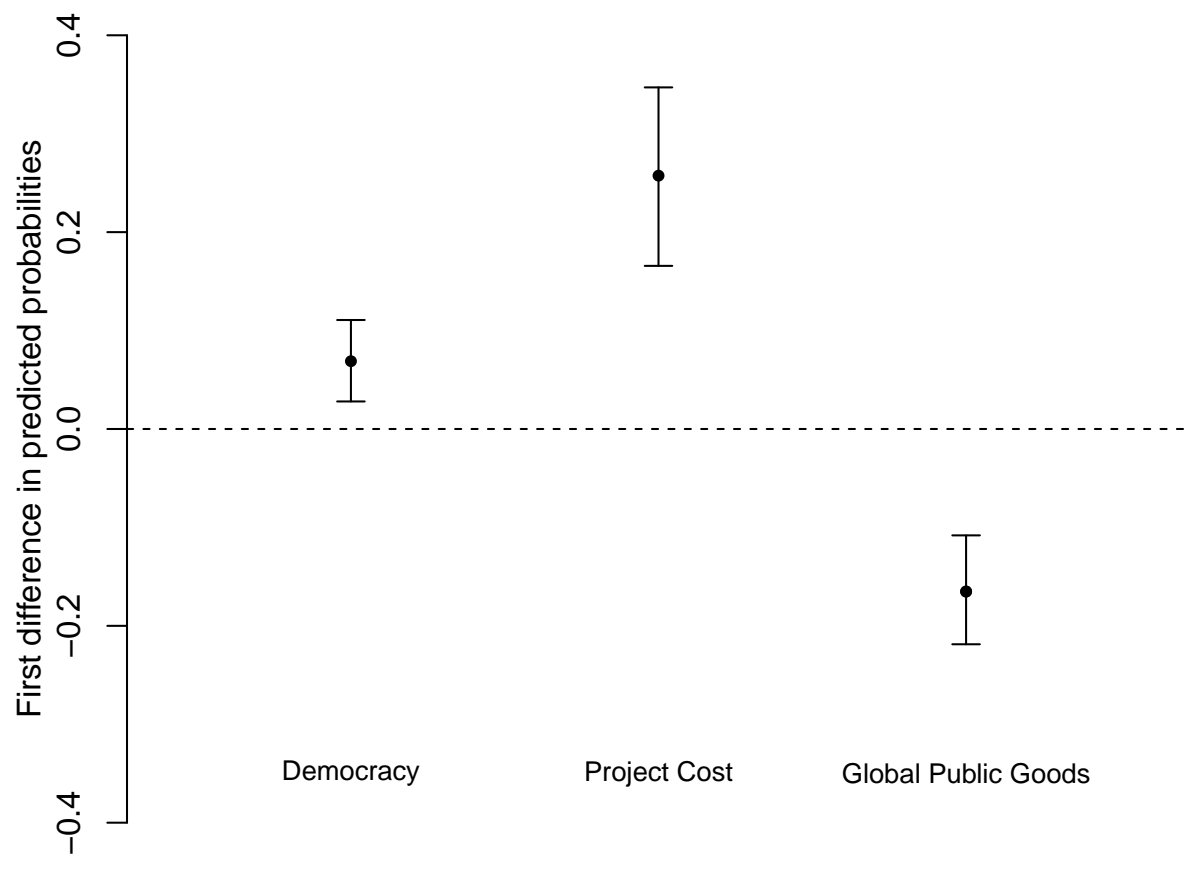

Figure 2: Substantive effects. The plot shows substantive effects for our main independent variables and illustrates changes from an autocratic to a democratic regime, from the mean project cost to one standard deviation above, and from local to global public goods. Simulation results are based on 1,000 draws from a multivariate normal distribution for model (1), while holding continuous variables at their means and discrete variables at their median values. Error bars indicate $95 \%$ confidence intervals. 


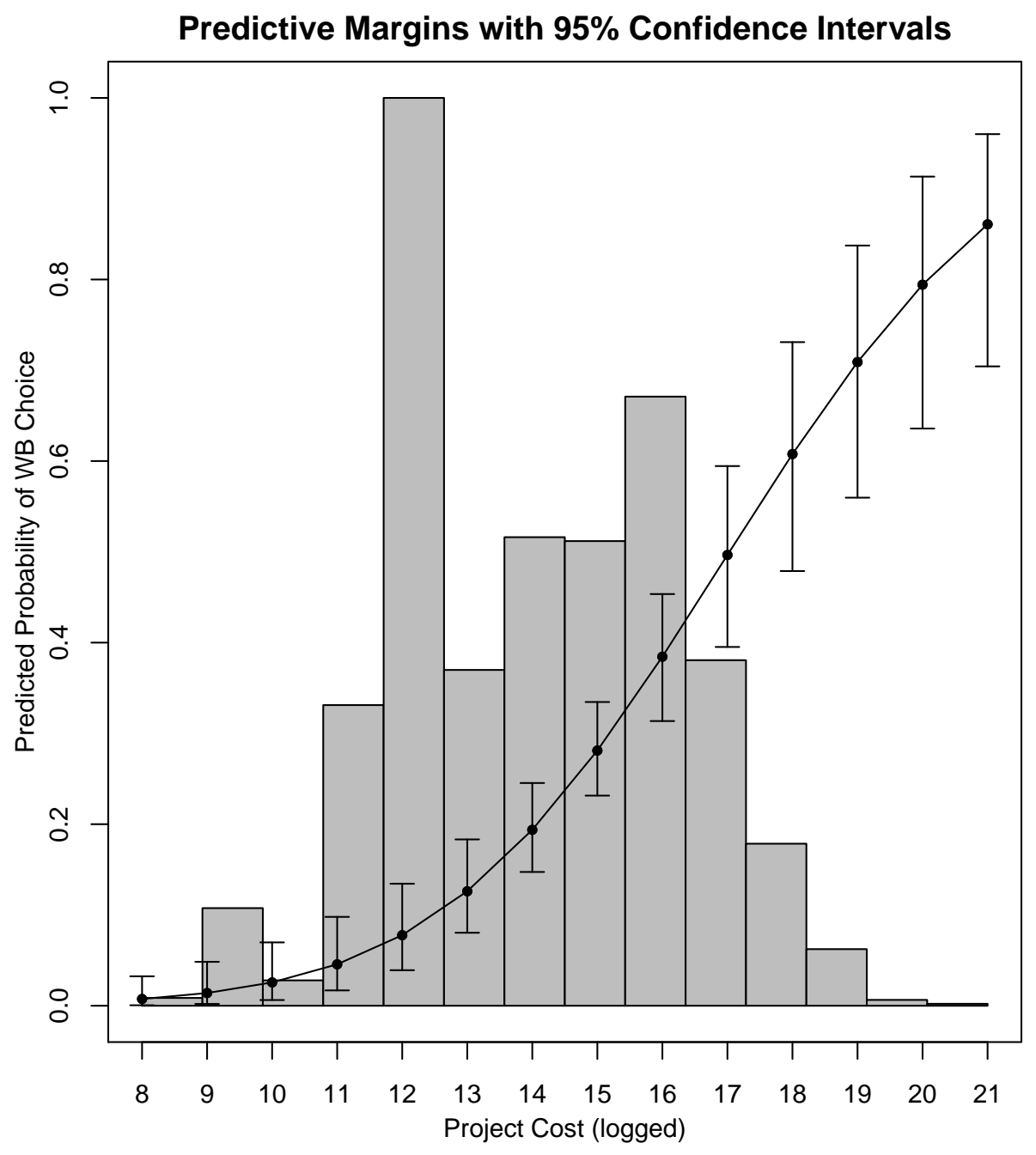

Figure 3: Predicted probability of WB selection by project size. Predicted probabilities and confidence intervals are again based on model (1) from our main regression results table above. Error bars indicate $95 \%$ confidence intervals. 
Main results

\begin{tabular}{|c|c|c|c|c|c|c|c|c|c|}
\hline & $\begin{array}{c}(1) \\
\text { Model }\end{array}$ & $\begin{array}{c}(2) \\
\text { Model }\end{array}$ & $\begin{array}{c}(3) \\
\text { Model }\end{array}$ & $\begin{array}{c}(4) \\
\text { Model }\end{array}$ & $\begin{array}{c}(5) \\
\text { Model }\end{array}$ & $\begin{array}{c}(6) \\
\text { Model }\end{array}$ & $\begin{array}{c}(7) \\
\text { Model }\end{array}$ & $\begin{array}{c}(8) \\
\text { Model }\end{array}$ & $\begin{array}{c}(9) \\
\text { Model }\end{array}$ \\
\hline Democracy & $\begin{array}{c}0.255^{* * *} \\
(0.075)\end{array}$ & $\begin{array}{c}0.335^{* * *} \\
(0.095)\end{array}$ & $\begin{array}{c}0.330^{* * *} \\
(0.110)\end{array}$ & $\begin{array}{c}0.290^{* *} \\
(0.115)\end{array}$ & $\begin{array}{l}0.198^{*} \\
(0.120)\end{array}$ & $\begin{array}{l}0.208^{*} \\
(0.122)\end{array}$ & $\begin{array}{l}-0.004 \\
(0.149)\end{array}$ & $\begin{array}{c}0.132 \\
(0.129)\end{array}$ & $\begin{array}{c}0.235^{* *} \\
(0.118)\end{array}$ \\
\hline Project Cost (logged) & $\begin{array}{c}0.285^{* * *} \\
(0.050)\end{array}$ & $\begin{array}{c}0.268^{* * *} \\
(0.055)\end{array}$ & $\begin{array}{c}0.253^{* * *} \\
(0.056)\end{array}$ & $\begin{array}{c}0.254^{* * *} \\
(0.057)\end{array}$ & $\begin{array}{c}0.261^{* * *} \\
(0.056)\end{array}$ & $\begin{array}{c}0.256^{* * *} \\
(0.055)\end{array}$ & $\begin{array}{c}0.414^{* * *} \\
(0.031)\end{array}$ & $\begin{array}{c}0.132^{* * *} \\
(0.051)\end{array}$ & $\begin{array}{c}0.301^{* * *} \\
(0.056)\end{array}$ \\
\hline Global Public Good & $\begin{array}{c}-0.477^{* * *} \\
(0.083)\end{array}$ & $\begin{array}{c}-0.459^{* * *} \\
(0.085)\end{array}$ & $\begin{array}{c}-0.439^{* * *} \\
(0.095)\end{array}$ & $\begin{array}{c}-0.443^{* * *} \\
(0.094)\end{array}$ & $\begin{array}{c}-0.513^{* * *} \\
(0.100)\end{array}$ & $\begin{array}{c}-0.521^{* * *} \\
(0.103)\end{array}$ & $\begin{array}{c}-0.558^{* * *} \\
(0.126)\end{array}$ & $\begin{array}{c}-0.594^{* * *} \\
(0.129)\end{array}$ & $\begin{array}{c}-0.513^{* * *} \\
(0.101)\end{array}$ \\
\hline GDP p.c. (logged) & & $\begin{array}{l}-0.059 \\
(0.058)\end{array}$ & $\begin{array}{l}-0.117 \\
(0.076)\end{array}$ & $\begin{array}{c}-0.166^{* *} \\
(0.076)\end{array}$ & $\begin{array}{c}-0.168^{* *} \\
(0.069)\end{array}$ & $\begin{array}{c}-0.159^{* *} \\
(0.074)\end{array}$ & $\begin{array}{c}-0.170^{* *} \\
(0.077)\end{array}$ & $\begin{array}{c}-0.191^{* * *} \\
(0.073)\end{array}$ & $\begin{array}{c}-0.175^{* *} \\
(0.075)\end{array}$ \\
\hline Population (logged) & & $\begin{array}{c}0.068^{* *} \\
(0.031)\end{array}$ & $\begin{array}{l}0.063^{*} \\
(0.036)\end{array}$ & $\begin{array}{l}-0.042 \\
(0.043)\end{array}$ & $\begin{array}{l}-0.020 \\
(0.046)\end{array}$ & $\begin{array}{l}-0.033 \\
(0.052)\end{array}$ & $\begin{array}{c}-0.155^{* * *} \\
(0.054)\end{array}$ & $\begin{array}{l}-0.056 \\
(0.044)\end{array}$ & $\begin{array}{l}-0.038 \\
(0.046)\end{array}$ \\
\hline Corruption & & & $\begin{array}{c}-0.118^{* *} \\
(0.054)\end{array}$ & $\begin{array}{l}-0.090^{*} \\
(0.051)\end{array}$ & $\begin{array}{l}-0.089^{*} \\
(0.053)\end{array}$ & $\begin{array}{l}-0.058 \\
(0.052)\end{array}$ & $\begin{array}{l}-0.102 \\
(0.064)\end{array}$ & $\begin{array}{l}-0.099 \\
(0.063)\end{array}$ & $\begin{array}{l}-0.087 \\
(0.058)\end{array}$ \\
\hline Investment Profile & & & $\begin{array}{l}-0.032 \\
(0.030)\end{array}$ & $\begin{array}{l}-0.037 \\
(0.030)\end{array}$ & $\begin{array}{l}-0.029 \\
(0.032)\end{array}$ & $\begin{array}{l}-0.024 \\
(0.033)\end{array}$ & $\begin{array}{c}-0.078^{* *} \\
(0.035)\end{array}$ & $\begin{array}{l}-0.036 \\
(0.039)\end{array}$ & $\begin{array}{l}-0.031 \\
(0.032)\end{array}$ \\
\hline IBRD Projects (cum. \#) & & & & $\begin{array}{c}0.068^{* * *} \\
(0.019)\end{array}$ & $\begin{array}{c}0.088^{* * * *} \\
(0.024)\end{array}$ & $\begin{array}{c}0.088^{* * *} \\
(0.025)\end{array}$ & $\begin{array}{c}0.180^{* * *} \\
(0.024)\end{array}$ & $\begin{array}{c}0.087^{* * *} \\
(0.020)\end{array}$ & $\begin{array}{c}0.093^{* * *} \\
(0.024)\end{array}$ \\
\hline WB Executive Board Member & & & & $\begin{array}{l}-0.091 \\
(0.111)\end{array}$ & $\begin{array}{l}-0.072 \\
(0.113)\end{array}$ & $\begin{array}{l}-0.093 \\
(0.122)\end{array}$ & $\begin{array}{l}-0.077 \\
(0.147)\end{array}$ & $\begin{array}{c}0.028 \\
(0.141)\end{array}$ & $\begin{array}{l}-0.061 \\
(0.112)\end{array}$ \\
\hline Security Council Member & & & & & $\begin{array}{c}-0.552^{* * *} \\
(0.150)\end{array}$ & $\begin{array}{c}-0.501^{* * *} \\
(0.159)\end{array}$ & $\begin{array}{c}-0.525^{* * *} \\
(0.174)\end{array}$ & $\begin{array}{c}-0.588^{* * *} \\
(0.147)\end{array}$ & $\begin{array}{c}-0.581^{* * *} \\
(0.154)\end{array}$ \\
\hline Region Fixed Effects & No & Yes & Yes & Yes & Yes & Yes & Yes & Yes & Yes \\
\hline Cubic Time Polynomial & Yes & Yes & Yes & Yes & Yes & Yes & Yes & Yes & Yes \\
\hline Observations & 1949 & 1925 & 1503 & 1503 & 1321 & 1260 & 1004 & 808 & 1166 \\
\hline Pseudo $R^{2}$ & 0.217 & 0.229 & 0.207 & 0.225 & 0.247 & 0.237 & 0.366 & 0.152 & 0.267 \\
\hline Correct Predictions in $\%$ & 81.89 & 82.03 & 79.44 & 80.97 & 81.00 & 80.63 & 82.47 & 70.30 & 80.45 \\
\hline
\end{tabular}

Standard errors in parentheses

Dependent Variable: World Bank Implemented Project.

Models (6) and (7) exclude years before 1994 and after 2006.

Model (8) excludes enabling activity projects.

Model (9) excludes multifocal projects.

All standard errors are clustered by country.

${ }^{*} p<0.10,{ }^{* *} p<0.05,{ }^{* * *} p<0.01$

Table 1: Results from the probit model with standard errors clustered by country. 